\title{
Molecular Changes of Titin in Left Ventricular Dysfunction as a Result of Chronic Hibernation
}

\author{
Jannie Ausma', Dieter Fürst'ㄹ, Fred Thoné3, Bharati Shivalkar", \\ Willem Flameng ${ }^{4}$, Klaus Weber ${ }^{2}$, Frans Ramaekers ${ }^{1}$ and Marcel Borgers ${ }^{1.3}$ \\ ${ }^{1}$ Department of Molecular Cell Biology E Genetics, Cardiovascular Research Institute Maastricht, \\ University of Limburg. Maastricht, The Netherlands, ${ }^{2}$ Department of Biochemistry. Max Planck \\ Institute for Biophysical Chemistry, Goettingen, Germany, ${ }^{3}$ Department of Morphology, Life Sciences, \\ Janssen Research Foundation, Beerse. Belgium, ${ }^{4}$ Department of Cardiovascular Surgery, Catholic \\ University of Leuven, Belgium.
}

(Received 20 September 1994, accepted in revised form 22 October 1994)

\begin{abstract}
J. Ausma, D. Fürst, F. Thoné. B. Shivalkar. W. Flameng. K. Weber. F. Ramaekers and M. Borgers. Molecular Changes of Titin in Left Ventricular Dysfunction as a Result of Chronic Hibernation. Journal of Molecular and Cellular Cardiology (1995) 27, 1202-1212. Cardiomyocytes of chronic hibernating myocardium are aflected by partial to complete loss of sarcomeres, accumulation of glycogen, adaptations in size and shape of mitochondria. reorganisation of nuclear chromatin and depletion of sarcoplasmic reticulum. The nature of these changes, which from a purely morphologic viewpoint are akin to dedifferentiation, needed further clarification at the molecular level. For this purpose we have studied the expression and reorganization of titin, one of the earliest markers of cardiomyocyte differentiation. By use of monoclonal antibodies, recognizing different epitopes distributed over the whole length of the titin molecule, we were able to detect changes in its molecular organization as a result of chronic hibernation. The epitopes of the titin molecule attached to the Z-disc and those present close to the $M$-line remained detectable at all stages of hibernation. while epitopes at the A-I junction and parts of the myosin anchoring region of the molecule became masked or were lost. A fragmented or punctuated appearance of the titin staining pattern with antibodies to A-I junction related epitopes is found in cells which we consider to represent a more advanced stage of dedifferentiation. Changes in the distribution of the titin molecule or its molecular environment in hibernating myocardium resemble at least in part changes occurring during muscle cell differentiation, although in reversed order.
\end{abstract}

Key Words: Human heart failure; Chronic hibernating myocardium; Cardiomyocyte; Titin; Dedifferentiation.

\section{Introduction}

The term "hibernating myocardium" was coined by Rahimtoola (1985) to describe a state of left ventricular dysfunction in patients with coronary artery disease in the absence of myocardial infarction. This process is, at least partially, reversible upon restoration of blood flow to the affected segment. The hibernating response of the heart has been considered as an act of self preservation to cope with a reduced myocardial blood flow (Rahimtoola. 1989). The recovery of function is described to be either rather quick (acute hibernation) or slow to very slow (chronic hibernation) (Rahimtoola, 1989; Ross, 1991; Schelbert, 1991).

Recently Borgers et al. (1993a,b) described the morphologic changes of cardiac biopsies obtained from 98 patients with left ventricular ischemic dys-

Please address all correspondence to: J. Ausma, Department of Molecular Cell Biology \& Genetics, University of Limburg, P.O. Box 616, 6200 MD Maastricht, The Netherlands. 
function. The typical structural changes, noted in cardiomyocytes of almost all patients, included loss of sarcomeres, the presence of abundant plaques of glycogen, loss of sarcoplasmic reticulum, occurrence of rough endoplasmic reticulum, shape changes of mitochondria and redistribution of nuclear chromatin. It was proposed that segments in which these structural changes prevail are characteristic of chronic hibernating myocardium and most probably are those that do not recover immediately after revascularization. Instead they might show a delayed recovery of function (weeks to months), because structural remodeling requires time in order to regain sufficient contractile material (Rahimtoola, 1989: Schelbert, 1991; Vanoverschelde et al., 1993). The characteristic change of hibernating cells concerns the replacement of contractile material (sarcomeres) by glycogen, a phenomenon that always starts in the perinuclear area of the cell and gradually extends towards the periphery in most altered cells. Since the lack of contractile filaments. the presence of accumulated glycogen (Manasek, 1986) and the preference of glucose over fatty acids as energy source (Harary, 1979) are characteristic features of embryonic cells. these criteria are considered as hallmarks suggesting that hibernating cells are going through a process of dedifferentiation.

In biopsies derived from patients with chronic hibernating myocardium the expression, organization and assembly of markers of cardiac cell development were studied to support the dedifferentiation hypothesis of hibernating cells. Titin was chosen as a dedifferentiation marker. Titin is a giant elastic protein of half sarcomere length, spanning the distance from the Z- to M-line (Fürst et al., 1988; 1989a). Protein sequences derived from cDNA cloning show that the carboxyterminal end of titin is at the M-band (Labeit et al., 1992). It is one of the earliest markers of cardiomyocyte differentiation (Tokuyasu and Maher, 1987a; Wang et al., 1988a; Schaart et al., 1989; Schultheiss et al., 1990; Van der Loop et al., 1992). In this study the sequence of organizational and redistributional changes of titin in hibernating myocardial cells, were monitored with antibodies to different epitopes of the titin molecule.

\section{Materials and Methods}

\section{Patients}

The human cardiac tissue material used in this study consisted of transmural biopsies obtained from 17 patients at the time of coronary bypass surgery. All patients gave their informed consent. The study was approved by the local ethical committees for research. The detailed individual patient characteristics are described in previous papers (Vanoverschelde et al., 1993; Maes et al., 1994). In brief, all patients had severe LAD stenosis and marked anterior wall abnormalities as evaluated by angiography and 2D echocardiography. The viability of the myocardium was verified by Positron Emission Tomography (PET) and by the assessment of function 3-6 months after coronary bypass surgery. All patient material dealt with in this paper fulfilled the criteria of chronic hibernation as defined previously (Vanoverschelde et al.. 1993; Maes et al., 1994).

\section{Morphologic evaluation}

Of all patients a first biopsy was fixed for a minimum of $2 \mathrm{~h}$ in $3 \%$ glutaraldehyde buffered with $90 \mathrm{~mm}$ $\mathrm{KH}_{2} \mathrm{PO}_{4}$, washed in the buffer and postixed for $1 \mathrm{~h}$ in $2 \% \mathrm{OsO}_{4}$ buffered with $50 \mathrm{~mm}$ veronal acetate, dehydrated in a graded series of ethanol and embedded in epoxy resin (Epon) (Flameng et al.. 1984). Light microscopic evaluation of morphologic changes was performed on $2 \mu \mathrm{m}$ thick sections of Epon-embedded biopsies, which were stained with periodic acid Schiff (PAS) and $0.1 \%$ toluidine blue to quantify the glycogen content and the loss of myofibrils. The degree of cellular change was evaluated in cells where the nucleus was visible in the plane of the section. The number of cells affected by myolysis was obtained by evaluating at least 200 cells per biopsy.

Left ventricle biopsies derived from seven donor hearts, which were either used for orthotopic transplantation or homograft prelevation, also used in a previously published study (Borgers et al., 1993b), were treated as above and served as non-ischemic controls.

\section{Indirect immunofluorescence assays}

A second biopsy of the hibernating myocardium was quickly frozen in isopentane pre-cooled with liquid nitrogen. Thick sections $(5 \mu \mathrm{m})$ were air-dried before use, and treated with $0.5 \%$ Triton X-100 (BDH Chemicals Ltd., Poole, UK) in phosphatebuffered saline (PBS) for $5 \mathrm{~min}$ at room temperature, followed by washing in PBS. The sections were incubated with the primary antibodies for $45 \mathrm{~min}$ at room temperature and washed with PBS (three steps of $10 \mathrm{~min}$ each). They were subsequently incubated with the secondary, fluorescein isothiocyanate (FITC) conjugated goat-anti-mouse Igsubclass specific antibody [Southern Biotechnology 
Associates (SBA) Inc., Birmingham. USA], or goatanti-rabbit antibody (SBA) for polyclonal antisera for $45 \mathrm{~min}$ and then washed in PBS (three steps of $10 \mathrm{~min}$ each).

In the double-labeling procedure the immunostaining steps were repeated with a second primary antibody of another Ig-subclass, the sections were washed in PBS and then incubated for $45 \mathrm{~min}$ with the secondary. Texas Red conjugated Ig-subclass specific antibody (SBA, Birmingham, AL, USA).

After these immunohistochemical procedures the sections were placed in distilled water for $5 \mathrm{~min}$, followed by post-fixation in methanol for $5 \mathrm{~min}$. The sections were air-dried and mounted in Mowiol (Hoechst, Frankfurt a.M., Germany) (Osborn and Weber, 1982). Nuclei were routinely stained with 4'-6-diamidine 2-o-phenylindole (DAPI: Sigma Chemicals, St Louis, MO, USA) in a dilution of 1 : 10000 with PBS. As a control, application of the first antibody was omitted.

\section{Confocal scanning laser microscopy}

Double label immunostained myocardium sections were observed with a Bio-Rad MRC-600 confocal scanning laser miscroscope (Bio-Rad Laboratories, Richmond, CA. USA) equipped with a Krypton/ Argon mixed gas laser (Ion Laser Technology, Salt Lake City, UT, USA) with two separate wavelengths for the excitation of fluorescein isothiocyanate $(488 \mathrm{~nm})$ and Texas Red (568 nm) and mounted on a Zeiss Axiophot microscope (Carl Zeiss, Oberkochen, Germany).

\section{Antibodies}

The following antibodies were used in this study the epitopes of the titin antibodies have been schematically presented in Fig. 1): (1) pTitin, a rabbit polyclonal antibody against titin which reacts with the $\mathrm{A}$ band and the A-I junction but not with the I-band or the Z-disc (Gassner, 1986). (2) A mouse monoclonal antibody 9D10 to titin. This antibody recognizes an epitope in the I-band at the A-I junction in skeletal and cardiac muscle (Wang and Greaser, 1985; Wang et al., 1988a; Greaser et al., 1989; Handel et al., 1989). The 9D10 monoclonal antibody was developed by M. Greaser and obtained from the Developmental Studies Hybridoma Bank maintained by the department of Pharmacology and Molecular Sciences, Johns Hopkins University School of Medicine. Baltimore MD 21205, USA and the department of Biology, University of Iowa, Iowa City
IA. USA, under contract N01-HD-2-3114 from the NICHD. (3) T30, a mouse monoclonal titin antibody which reacts with repetitive sequences of the $A$ band. T30 detects five of the seven C-stripes, that coincide with binding places for myosin associated proteins, i.e. the C-protein and H-protein (Fürst et al., 1989a). (4) T31, a mouse monoclonal titin antibody which reacts with repetitive sequences of the A-band. T31 detects both P-stripes that coincide with binding places of the H-protein (Fürst et al., 1989a). (5) T12, a mouse monoclonal titin antibody which reacts with an epitope in the I-band just before the Z-disc (Fürst et al., 1988). (6) SR-1. a mouse monoclonal antibody recognizing striated muscle $\alpha$-actin (Skalli et al., 1988) (DAKO A/S. Glostrup, Denmark). (7) The mouse monoclonal desmin antibodies DE-R-11 (Debus et al., 1983) (DAKO A/S, Glostrup, Denmark) and RD301 (Schaart et al., 1989; Raats et al., 1991). (8) MF 20, a mouse monoclonal antibody recognizing all forms of myofibrillar myosin heavy chain (Bader et al.. 1982). The MF 20 monoclonal antibody was developed by D. Fischman and obtained from the Developmental Studies Hybridoma Bank maintained by the department of Pharmacology and Molecular Sciences, Johns Hopkins University School of Medicine, Baltimore MD 21205. USA and the department of Biology, University of Iowa, Iowa City IA, USA, under contract N01-HD-2-3114 from the NICHD. (9) MF 30, a mouse monoclonal antibody, it recognizes the S2 fragment of the myosin heavy chain of various neonatal and adult species (Bader et al., 1982). The MF 30 monoclonal antibody was developed by D. Fuschman and obtained from the Developmental Studies Hybridoma Bank maintained by the department of Pharmacology and Molecular Sciences, John Hopkins University School of Medicine, Baltimore MD 21205, USA and the department of Biology, University of Iowa, Iowa City IA, USA. under contract N01-HD-2-3114 from the NICHD. (10) The mouse monoclonal antibody TM311 which reacts with tropomyosin (Sigma Immunochemicals, St. Louis, USA). (11) The mouse monoclonal vimentin antibody RV203 (Schaart et al., 1991). In addition rhodamine-labeled phalloidin was used to stain F-actin (dilution 1:80 in PBS) (Molecular Probes Inc. Eugene, OR, USA).

\section{Results}

\section{Morphological changes}

The most important change in cellular substructure seen in a considerable number of myocardial cells 


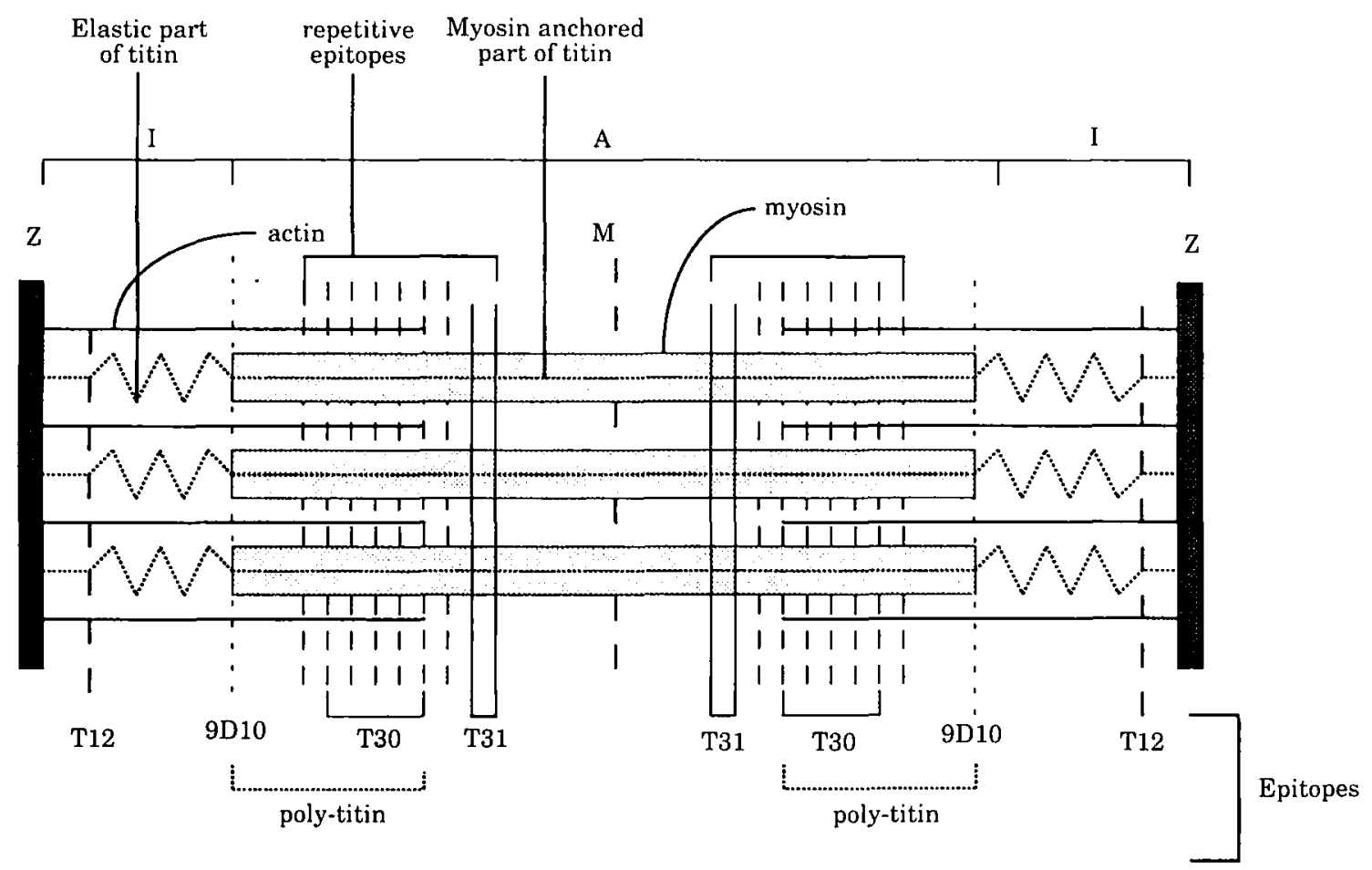

Figure 1 Schematic representation of the lopography of the epitopes recognized by the different anti-titin antibodies. $\mathrm{Z}$ : Z line, M: center of the M-band. A and I mark the anisotropic and isotropic bands respectively.

from chronic hibernating myocardial segments was the depletion of contractile material without loss of cell volume. Loss of contractile material was in many cells limited to the vicinity of the nucleus, but in others it comprised the bulk of the cytoplasm. leaving only a few or no sarcomeres at the periphery of the cell (Fig. 2a). The myolytic areas, being the spaces in which myofilaments were dissolved, became occupied by glycogen and many small mitochondria (Fig. 2b). Cells were considered as affected by the process of myolysis when more than $10 \%$ of the cell volume was occupied by glycogen (Borgers et al.. $1993 \mathrm{~b}$ ). Within a group of 17 patients $25 \pm 15 \%$ of all cells were affected. An increase in connective tissue was consistently observed in areas in which structurally affected myocardial cells prevailed (Fig. 2a).

\section{Immunofluorescence assays}

In parts of the myocardium which contained only normally structured cells the antibodies pTitin, T30 and 9D10, which label three different epitopes in the A-I junction part of titin (Fig. 1), showed a similar double-banded cross-striated pattern (Fig. 3a). Hibernating cells with perinuclear myolysis showed the same distribution pattern. However, in those cells the cross-striated staining pattern was limited to the peripherally located sarcomere strands (Fig. 3b). In most hibernating cells with a severe degree of myolysis, the double- banded staining pattern was absent for the three antibodies. This disappearance of a titin cross-striated staining pattern for the antibodies 9D10, T30 and PTitin seems to be a stepwise process, the earliest observed change was the loss of double-banded titin staining and the occurrence of the titin staining pattern as single bands (Fig. 3c). In addition, the staining intensity was markedly lower as compared to normal cells. In more severely affected cells the striation patterns of titin normally crossing the whole cardiomyocyte, was limited to certain parts of the cell. The titin striations were lost, only locally some short titin striations remained (Fig. $3 \mathrm{c}$ ). In the most severely affected areas, 9D10, T30 and pTitin showed an even more distinct decrease of the titin cross-striations. Many cells lost their cross-striated staining pattern or showed a punctate (dot-like) staining reaction (Fig. 3d).

In contrast to pTitin, 9D10 and T30 the crossstriated staining pattern of $\mathrm{T} 12$, which recognizes an epitope at the I-band just before the Z-line, and T31 recognizing two repetitive epitopes close to the centre of the A band, were retained throughout the 


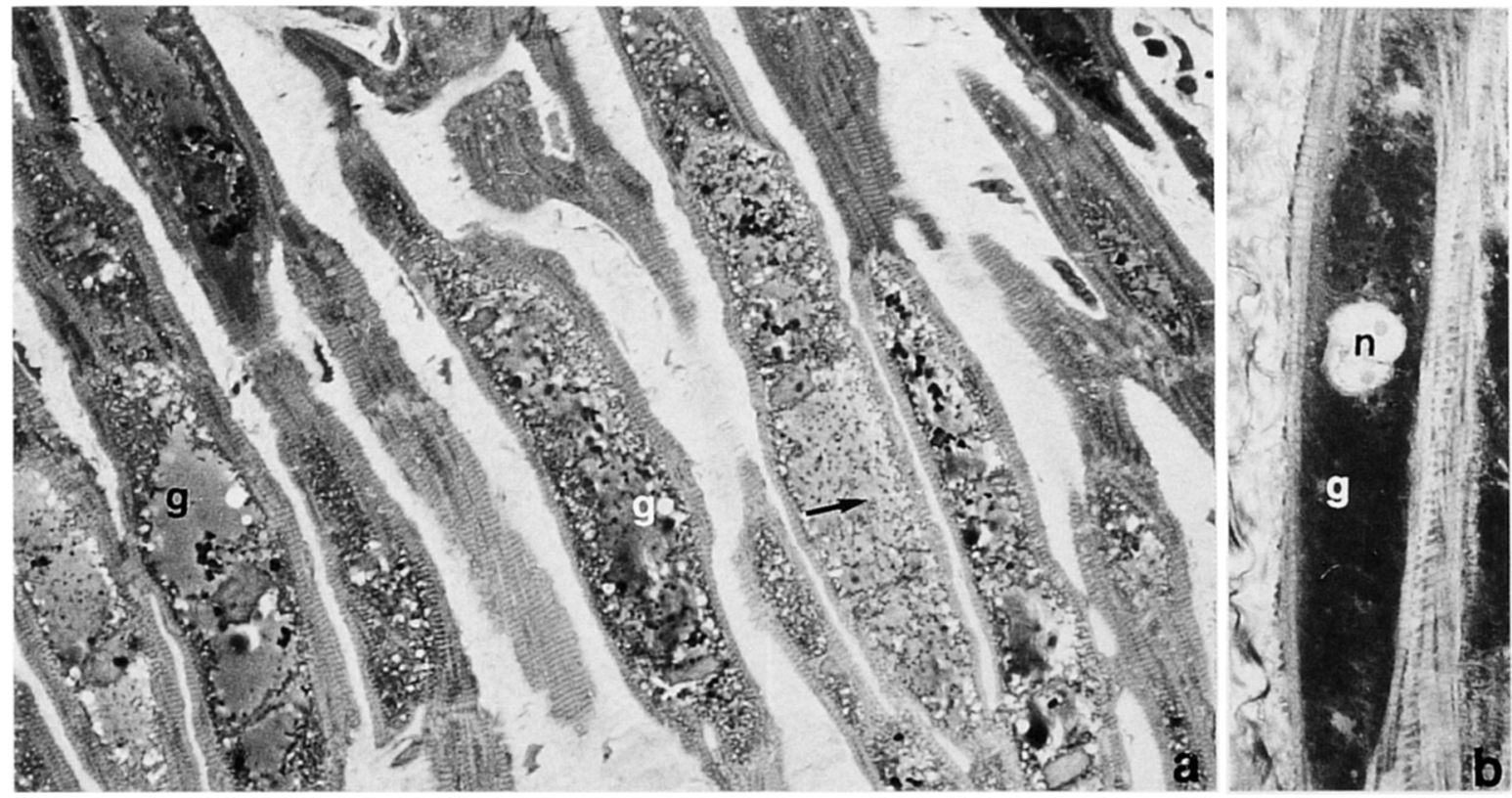

Figure 2 Light microscopy of morphologic changes in chronic hibernating myocardium. (a) Two micron thick section of an affected area, stained with toluidine blue showing that the centers of most cells are myolytic. The myolytic areas are filled with amorphous material (glycogen, g) intermingled with small dots (mitochondria, arrow). Increased amounts of connective tissue material surround the cardiomytes. Magnification: $\times 540$ ). (b) Severely hibernating cells with large amounts of glycogen $(\mathrm{g})$ seen as dark zones surrounding the nucleus ( $\mathrm{n}$ ) subsequent to PAS staining. Magnification: $\times 700$.

various stages of myolysis (Fig. 4a-d). With these two antibodies titin striations were seen at a regular distance in the sarcomeres of the hibernating cells. There were no differences in the staining patterns with these anti-titin antibodies in different zones of the chronic hibernating myocardium (Fig. 4a,c). From double-labeling immunofluorescence studies it was obvious that the organization of titin nearby the Z-line (T12) and close to the centre of the Aband (T31) was still intact while in the same cells the cross-striated titin staining patterns for epitopes at the first part of the A-band and A-I junction were completely lost (Fig. 4a,b and $4 \mathrm{c}, \mathrm{d}$ ).

In contrast to the titin disorganization, other sarcomeric proteins remained well organized in the sarcomeres. Even in zones with severe changes in 9D10, T30 and pTitin staining, actin, myosin, tropomyosin and desmin still showed clear crossstriations, similar to those as seen in the sarcomeres of normal myocardium. As an example. the staining pattern of desmin in relation to the titin 9D10 epitope is shown in Figure 5a and 5b. In Figure 5c and $5 \mathrm{~d}$ confocal laser scanning microscopic pictures of myosin and titin are shown. The sarcomeres in this figure have a clear cross-striated myosin pattern, while the titin epitope recognized by 9D10 is scarcely visible. $\alpha$-smooth muscle actin became reexpressed in chronic hibernating myocardium cells, but vimentin expression was not detected in the dedifferentiating cardiomyocytes.

In order to investigate the localization in relation to the Z- and $\mathrm{M}$-line and distance of different titin epitopes during stages of dedifferentiation of chronic hibernating myocardium confocal scanning laser microscopy analysis was performed. The titin epitopes recognized by $\mathrm{T} 31$ never coincide with the Z-disc (desmin positive), indicating that the titin epitopes at the centre of the A-band have not dramatically changed their position within the remaining sarcomeric structure.

\section{Discussion}

Cardiomyocytes of chronic hibernating myocardium undergo typical ulstrastructural changes of which the replacement of sarcomeres by glycogen is the hallmark (Borgers et al., 1993b; Ausma et al. 1994). These observations have been considered as morphologic indicators of cardiomyocyte dedifferentiation. In addition, recent studies (Ausma et al., 1995) showed that $\alpha$-smooth muscle actin, a protein that gradually disappears from cardiomyocytes during development, became re-expressed in hibernating cardiomyocytes. Also titin, which is one of the earliest sarcomeric proteins 

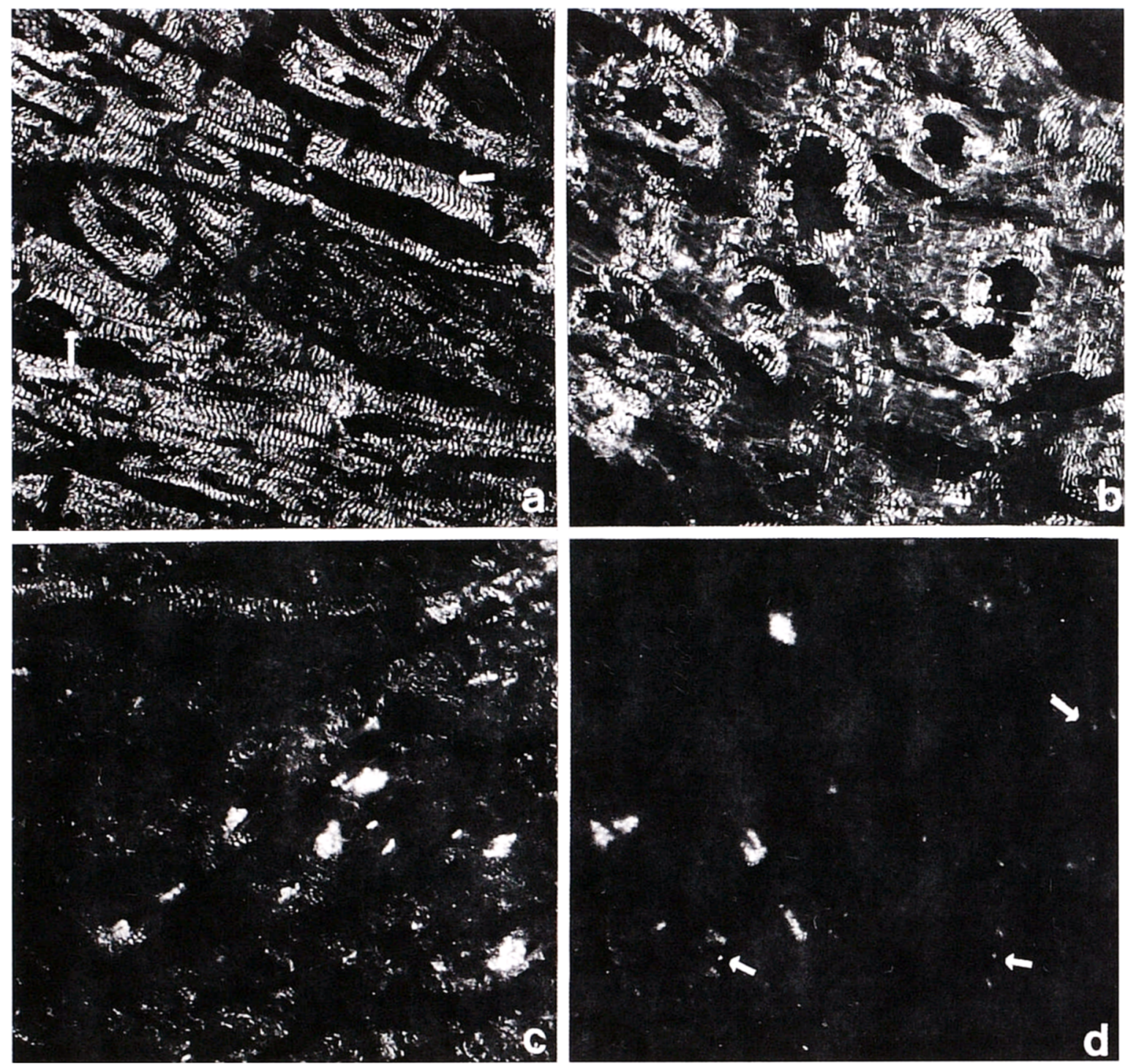

Figure 3 Immunofluorescence micrographs of frozen sections of myocardium of patients with chronic hibernation. incubated with antibodies against the A-I junction part of titin. As an example the 9D10 staining is shown. (a) Titin staining in a nearly normal pattern. Double-banded cross-striations are indicated by arrows. (b) Cells in which sarcomeres are located only at the periphery of the cell. Most of these cells showed typical double-banded striations at their periphery. (c) Marked decrease of titin staining in chronic hibernating myocardium: only short titin striations and titin punctations. (d) Only a residual staining is present (arrows). The large dots which are visible around the nuclei represent lipofuchsin autolluorescence. Magnification: $\times 500$.

during embryogenesis, appeared to change its immunocutochemical detectability in hibernating cardiomyocytes. Other sarcomeric and cytoskeletal proteins such as actin, myosin, tropomyosin and desmin remained intact in sarcomeres at the periphery of the hibernating cardiomyocytes.

Effects of hibernation on the titin molecular structure

Studying the organization of titin with monoclonal antibodies against different epitopes situated along this large molecule provides new insights into structural changes of this protein during hibernation. The use of antibodies directed to the epitopes of the titin molecule present at the A-band and the A-I junction of the sarcomere revealed that this part of the molecule is masked or lost in hibernating cells. On the other hand. the epitope of T12. localized in close proximity to the Z-line and the T31 epitope. known to be situated at the centre of the A-band. remained detectable during the process of heart muscle cell adaptation. These results strongly indicate a change in the structure of the titin molecules, in particular, in its normally rigid middle 

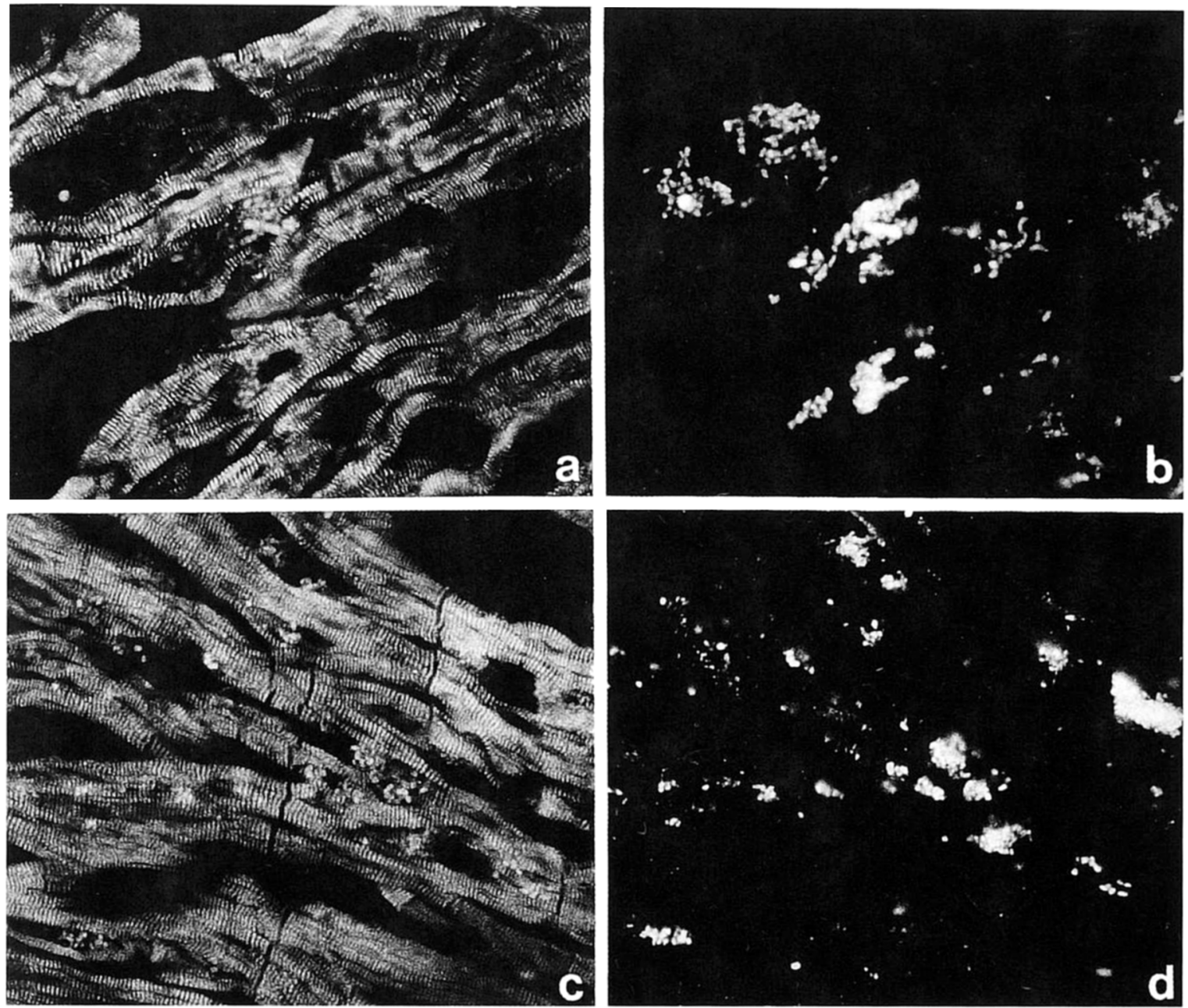

Figure 4 (a,b) Double-labeling of a section of chronic hibernating myocardium with two anti-titin antibodies, one which recognizes the I-band part of titin nearby the Z-line (T12) and the other recognizes the A-I junction part (9D10). Note that T12 staining remained intact in severely affected cardiomyocytes (a), while 9D10 staining was almost completely lost (b). (c,d) Double-labeling of a section of chronic hibernating myocardium with two anti-titin antibodies. one which recognizes the A-I junction part (9D10) and the other which recognizes the A-band part of titin nearby the M-line (T31). T31 staining remained intact in the severely affected cardiomyocytes (c), while 9D10 staining was totally absent (d).

part. In the N-terminus (Z-line part) and the Cterminus (M-line part) of titin seems to remain intact during hibernation. Changes at the molecular level, either occurring in the titin molecule itself or in its molecular assembly with other sarcomeric proteins, apparently start at the part of titin anchored to myosin (recognized by pTitin and T30) as well as the junction between the elastic and rigid part of the molecule (recognized by 9D10). The absence of titin staining at this part of the molecule can be the result of proteolytic degradation, but it is also possible that it results from a change in the molecular environment of the titin molecules. When analysed in more detail, T30 and T31 monoclonal antibodies were shown to recognize repetitive epitopes in the titin molecules, that coincide with the binding places of specific myosin associated proteins, i.e. C-protein and H-protein. The T31 epitope matches with the two P-stripes, which contain only the H-protein. The T30 epitope matches with five of the seven C-stripes, places on which both C-protein and H-protein are attached to myosin. It has been suggested that $\mathrm{C}$-protein interacts with titin (Fürst et al.. 1992. Koretz et al., 1993). Differences in titin epitope detectability during (de)differentiation might well be related to changes in the molecular environment of titin, resulting from a change in the interaction between $\mathrm{C}$-protein and titin.

The A-band region of titin has been shown to become extensible when it is detached from myosin (Wang et al., 1988b; Higuchi et al., 1992). Higuchi et al. (1992) also showed that during partial depolymerization of thick filaments, the anti-titin anti- 

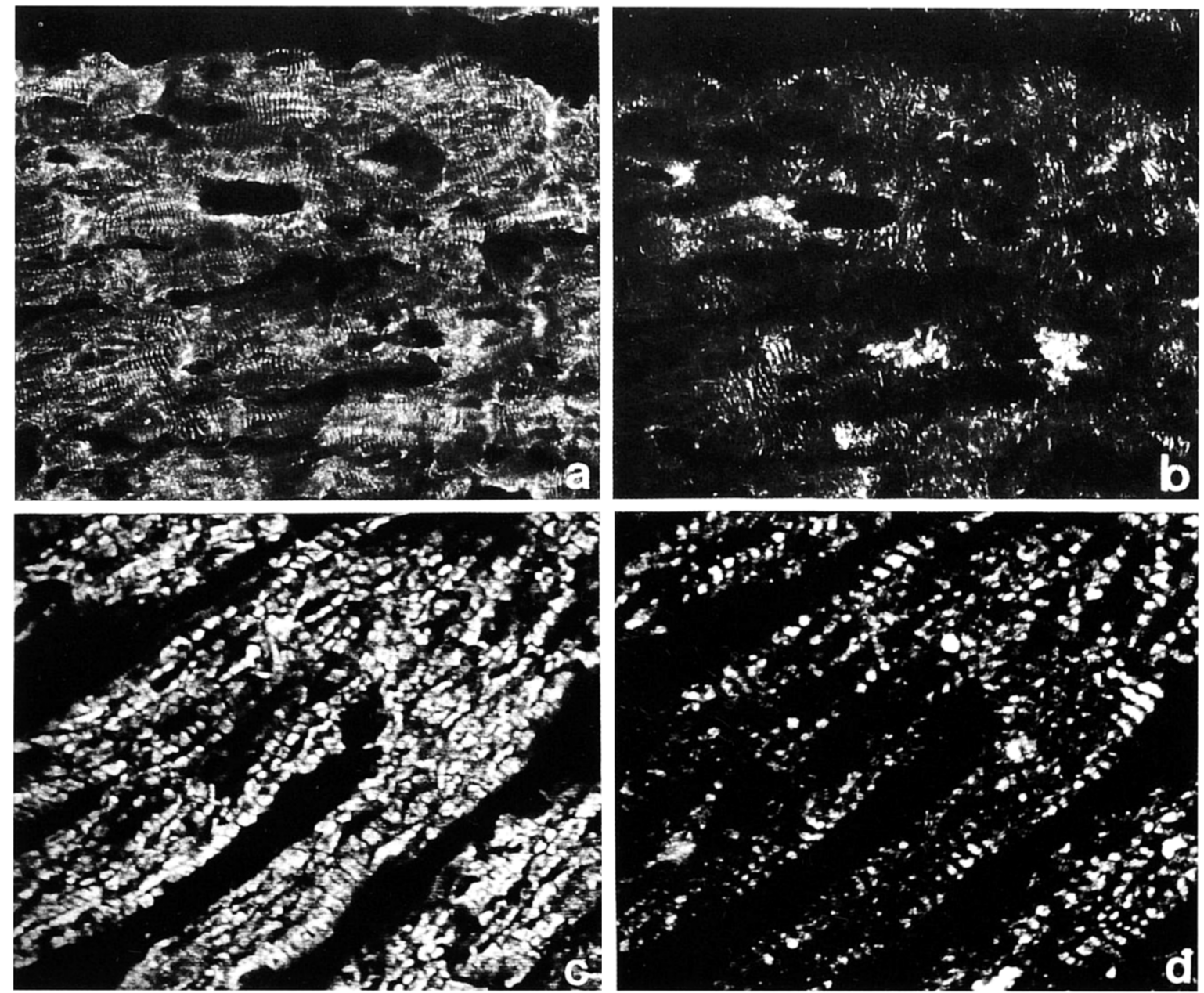

Figure 5 (a,b) Double-labeling of a section of chronic hibernating myocardium with desmin and titin (9D10). (a) Desmin staining still remains intact in these cells while (b) titin, on the other hand is only seen as spots and short striations. (c.d) Confocal laser scanning microscopy of a chronic hibernating segment with myosin staining (MF-20) display in a clear cross-striated pattern (c), whereas only some titin (9D10) is seen (d). Magnilication: a,b $\times 500: c, d$. $\times 1360$.

bodies recognizing a specific position in the A-band showed immunoreactivity at a constant distance from the M-line. As the thick filament was almost completely depolymerized, these titin antibodies were found to localize at the Z-line. suggesting detachment of the titin molecule from the M-line anchoring. In chronic hibernating myocardium on the other hand, the thick filaments are still present and as a result $\mathrm{T} 31$ immunostaining is still normal, indicating that titin is not detached from the Mline of the thick filaments.

Changes in titin during chronic hibernation: differentiation in reverse?

Borisov (1991) has described that cardiac muscle cells at early, intermediate and terminal stages of differentiation are capable of adaptive remodeling of their contractile system both in vivo and in vitro. This implies that dedifferentiated cardiomyocytes can redifferentiate again. Moreover, Sharp et al. (1993) established that in verapamil-arrested cultured neonatal rat heart cells, in which initially a steep reduction in the amount of actin was observed, the process could be entirely reversed upon omission of the drug. During chronic hibernation hypo/ akinesia may lead to a similar reduction in the amount of contractile material, hence indicating a process of dedifferentiation to a state comparable with neonatal cardiomyocytes.

The loss of the titin epitope stained by antibody 9D10 in chronic hibernating myocardial cells started with the fragmentation of titin striations, ultimately leading to dot-like staining. A similar punctate pattern was also seen with 9D10 during cardiac and skeletal myofibrillogenesis at the onset 
of the formation of myofibrils (Tokuyasu and Mayer, 1987b; Wang et al., 1988a.b; Schaart et al., 1989; Schultheiss et al., 1990: Van der Loop et al., 1992). and during skeletal muscle cell differentiation in culture (Van der Ven et al., 1992; 1993).

The persistence of a "normal" T31 epitope staining pattern in affected cardiomyocytes seems in conflict with the idea that titin organization starts at the Z-line and progresses towards the M-band (Fürst et al., 1989b) as deduced from comparing changing titin organization during in vivo or in vitro differentiation processes with that of apparently dedifferentiating hibernating cells. During myofibril formation in mouse skeletal muscle the T30 and T31 epitopes of titin are revealed simultaneously (Fürst, unpublished observation). However, during dedifferentiation in hibernating myocardium, the T31 epitope is still detectable, whereas the T30 epitope is not. It is assumed that the adaptive dedifferentiation process during hibernation takes considerably more time than embryonic differentiation. Therefore, it is possible that such subtle differences in the organization of distinct A-band titin epitopes cannot be detected during skeletal muscle development of the mouse, because of the relatively high speed of differentiation. Likewise, the localization of titin A-band epitopes has not yet been documented in developing human cardiac muscle. Therefore, it cannot be excluded that species differences as well as variations in the organization of the sarcomeres of skeletal and cardiac muscle cause this apparent discrepancy. Also, dedifferentiation of chronic hibernating myocardium is not complete, as indicated by the lack of vimentin expression. The most plausible explanation for the observed differences in titin organization during hibernation and myofibrillogenesis, respectively, may be that the dedifferentiation process is not completely reversible at all the steps of sarcomere assembly.

\section{Acknowledgements}

We are grateful to Dr D. Gassner for the gift of polyclonal anti-titin antibodies. We thank Dr G. van Eys and Dr G. Schaart for critically reading the manuscript.

\section{References}

Ausma J, Ramaekers F. Shival.kar B, Thoné F, Flameng W. Borgers $M$, 1994. Cellular adaptation in hibernating myocardium in man. In: Hori M. Maruyama
Y. Reneman RS, eds. Cardiac adaptation and failure. Springer-Verlag. Tokyo. 85-99.

Ausma J. Schaart G. Thoné F. Shivalkar B, Flameng W. DEPRÉ C. VANOVERSCHELde J-L, RAMAEKERS F, Borgers M, 1995. Chronic ischemic viable myocardium in man: aspects of dedifferentiation. Cardiovasc Pathol 4: 29-37.

BADER D. MASAKI 'T, FISCHMAN DA, 1982. Immunochemical analysis of myosin heavy chain during avian myogenesis in vivo and in vitro. $J$ Cell Biol 95: $763-770$.

BoRgERS M, FlamenG W, 1993a. Morphology of the acute and chronic ischemic myocardium in man. In: Piper $\mathrm{HM}$ and Preusse CJ. eds. Ischemia-reperfusion in Cardiac Surgery. Kluwer Academic Publishers, 353-375.

Borgers M. Thoné F, Wouters L, Ausma J, Shivalkar B, FLAMENG W, 1993b. Structural correlates of regional myocardial dysfunction in patients with critically coronary artery stenosis: chronic hibernation? Cardiovasc Pathol 2: 237-245.

Borisov AB, 1991. Myofibrillogenesis and reversible disassembly of myofibrils as adaptive reactions of cardiac muscle cells. Acta Physiol Scand S599: 71-80.

Debus E, WeBer K, OSBORN M, 1983. Monoclonal antibodies to desmin, the muscle specific intermediate filament. EMBO I 2: 2305-2312.

Flameng W, Wouters L, Sergeant P. LeWi P, Borgers M. Thoné F, Suy R, 1984. Multivariate analysis of angiographic histologic and electrocardiographic data in patients with coronary heart disease. Circulation 70: 7-17.

Fürst DO, Osborn M. Nave R, Weber K, 1988. The organization of titin filaments in the half-sarcomere revealed by monoclonal antibodies in immunoelectron microscopy: a map of ten non-repetitive epitopes starting at the $\mathrm{Z}$ line extends close to the $\mathrm{M}$ line. J Cell Biol 106: 1563-1572.

Fürst DO. Nave R, Osborn M. Weber K, 1989a. Repetitive titin epitopes with a $42 \mathrm{~nm}$ spacing coincide in relative position with known $\mathrm{A}$ band striations also identified by major myosin-associated proteins. An immunoelectron-microscopical study on myofibrils. J Cell Sci 94: 119-125.

Fürst DO, Osborn M, Weber K, 1989b. Myogenesis in the mouse embryo: Differential onset of expression of myogenic proteins and the involvement of titin in myofibril assembly. J Cell Biol 109: 517-527.

FÜRST DO, VINKEMEIER U, WEBER K, 1992. Mammalian skeletal muscle $C$-protein: purification from bovine muscle, binding to titin and the characterization of a full-length human cDNA. I Cell Sci 102: 769-778.

GASSNER D, 1986. Myofibrillar interaction of blot immunoaffinity-purified antibodies against native titin as studied by direct immunofluorescence and immunogold staining. Eur J Cell Biol 40: 176-184.

Greaser ML, HaNdel SE, WANG SM, Schultz E, Bulinski IC. LESSARD JL, 1989. Assembly of titin, myosin, actin and tropomyosin into myofibrils in cultured chick cardiomyocytes: In Stockdale F, Kedes L, eds. Cellular and molecular biology of muscle development. UCLA Symposium on molecular and cellular biology. New Series. Liss New York Vol 93: 246-257.

HANDEL SE, WANG SM, GREASER ML, SchulTz E, BULINSKI JC, LESSARD L, 1989. Skeletal muscle myofibrillogenesis as revealed with monoclonal antibody to titin in combination with detection of alpha and gamma isoforms of actin. Dev Biol 132: 35-44. 
HARARY I, 1979. Biochemistry of cardiac development: in vivo and in vitro studies. In: Berne RM et al. eds. Handbook of Physiology, section 2: The cardiovascular system. American Physiological Society, Baltimore, Vol I: $34-60$.

Higuchi H, SuzUKI T. Kimura S, Yoshoka T, MaruYama K, UMAZUME Y, 1992. Localization and elasticity of connectin (titin) filaments in skinned frog muscle fibres subjected to partial depolymerization of thick filaments. I Muscle Res Cell Motil 13: 285-294.

KORETZ JF, IRving TC, WANG K, 1993. Filamentous aggregates of native titin and binding of C-protein and AMP-deaminase. Arch Biochem Biophys 304: 305-309.

LABEIT S, GaUTEL M, LAKEY A. TRINICK J, 1982. Towards a molecular understanding of titin. EMBO J 11: 17111716.

Maes A, Flameng W, Nuyts J, Borgers M, Shivalkar B, Ausma J, Bormans G, Schiepers C, De Roo M, MORTELMANS L, 1994. Histological alterations in chronically hypoperfused myocardium. Correlation with PET findings. Circulation 90: 735-745.

MANASEK FJ, 1986. Mitosis in developing cardiac muscle. J Cell Biol 37: 191-196.

OSBORN M, WEBER K, 1982. Immunofluorescence and immunocytochemical procedure with affinity purified antibodies: tubulin-containing structures. Methods Cell Biol 24: 97-132.

RaATS FR, HENDERIK JB, VerdiJk M, VAN OORT FLG, GeraRds WLM, RAMAEKERS FCS, BloEMENDAL H, 1991. Assembly of the carboxy-terminally deleted desmin in vimentin free cells. Eur J Cell Biol 56: 84-103.

RaHimToOLA SH, 1985. A perspective on the three large multicenter randomized clinical trials of coronary bypass surgery for chronic stable angina. Circulation 72[Suppl. V]: 123-135.

RAHIMTOOLA SH, 1989. The hibernating myocardium. Am Heart J 117: 211-221.

Ross J, 1991. Myocardial perfusion-contraction matching. Implications for coronary heart disease and hibernation. Circulation 83: 1076-1083.

SCHaART G, Biebahn C, LANGmanN W, Ramaekers FCS, 1989. Desmin and titin expression in early postimplication mouse embryos. Development 107: 585596.

SchaArt G, Pieper FR, Kuypers HJH, Bloemendal H, RAMAEKERS FCS, 1991. Baby Hamster kidney (BHK$21 / \mathrm{Cl} 3$ ) cells can express striated muscle type proteins. Differentiation 46: 105-115.

SCHELBERT HR, 1991. Positron emission tomography for the assessment of myocardial viability. Circulation 84[Suppl. V]: 122-131.

Schultheiss T, Lin Z, Lu M-H, MuRRay J, Fischman DA, Weber K, Masaki T, Imamura M, Holtzer H, 1990.
Differential distribution of subsets of myofibrillar proteins in cardiac non-striated and striated myofibrils. J Cell Biol 110: 1159-1172.

Sharp WW, Terracio L. Borg TK. Samarel AM, 1993. Contractile activity modulates actin synthesis and turnover in cultured neonatal rat heart cells. Circ Res 73: 172-183.

Skalli O, Gabbiani G, Babaï F, Seemayer TA, Pizzolato G, SCḦ̈̈RH W, 1988. Intermediate filament proteins and actin isoforms as markers for soft tissue tumor differentiation and origin. II Rhabdomyosarcomas. Am J Path 130: 515-531.

TOKUYASU KT, MAHER PA, 1987a. Immunocytochemical studies of cardiac myofbrillogenesis in early chick embryos. I. Presence of immunofluorescent titin spots in premyofibril stages. J Cell Biol 105: 2781-2793.

TOKUYASU KT, MAHER PA, 1987b. Immunocytochemical studies of cardiac myofibrillogenesis in early chick embryos. II. Generation of $\alpha$-actinin dots within titin spots at the time of the first myofibril formation. J Cell Biol 105: 2795-2801.

VAN DER LOOP FTL, SCHAART G, LANGMANN W, RAMAEKERS FCS, VIEBAHN CH., 1992. Expression and organization of muscle specific proteins during early development stages of the rabbit heart. Anat Embryol 185: 439-450.

VAN DER VEn PMF, SchaART G, JaP PHK, Sengers RCA, STADHOUdERS AM, RAMAEKERS FCS, 1992. Differentiation of human skeletal muscle cells in culture: maturation as indicated by titin and desmin striation. Cell Tissue Res 270: 189-198.

VAN DER VEN PMF, SchaART G, Croes HJE, JAP PHK, GiNSEL LA, RAMAEKERS FCS, 1993. Titin aggregates associated with intermediate filaments align along stress fiber-like structures during human skeletal muscle cell differentiation. / Cell Sci 106: 749-759.

Vanoverschelde JLJ, Wijns W. Depré C, Esamri B. HeynDricks S, Borgers M. Bol A. Melin J, 1993. Mechanisms of chronic regional postischemic dysfunction in humans: New insights form the study on noninfarcted collateral dependent myocardium. Circulation 87: 1513-1523.

WANG S-M, GREASER ML, 1985. Immunocytochemical studies using a monoclonal antibody to bovine cardiac titin on intact and extracted myofibrils. I Muscle Res Cell Motil 6: 293-312.

WANG S-M, Greaser ML, Schultz E, Bulinski JC, Lin JJC, LESSARD J, 1988a. Studies on cardiac myofibrillogenesis with antibodies to titin, actin, tropomyosin and myosin. I Cell Biol 107: 1075-1083.

WANG K, WRIGHT J, 1988b. Sarcomere matrix of skeletal muscle - the role of thick filaments in the segmental extensibility of elastic thin filaments. Biophys $J$ 53: 25A. 